\title{
Logistic model of operational planning works terminal
}

\author{
Evgeniy Kolbachev ${ }^{1}{ }^{*}$, Natalya Napkhonenko ${ }^{2}$, Maryna Karayeva ${ }^{3}$, Dmytro Maloshtan ${ }^{4}$ \\ ${ }^{1}$ Platov South-Russian State Polytechnic University (Novocherkassk Polytechnic Institute)name of \\ M.I. Platov, (Novocherkassk) \\ ${ }^{2}$ Platov South-Russian State Polytechnic University (Novocherkassk Polytechnic Institute) name of \\ M.I. Platov, (Novocherkassk) \\ ${ }^{3}$ Platov South-Russian State Polytechnic University (Novocherkassk Polytechnic Institute) name of \\ M.I. Platov, (Novocherkassk) \\ ${ }^{4}$ Kremenchuk MykhailoOstrohradskyi National University, Ukraine
}

\begin{abstract}
The analysis of cargo terminals forwarding activity operational planning problems is provided and their main reasons are established; the existing approaches to improvement of operational planning system of transport infrastructure in theoretical researches of the Russian and foreign authors and also the accumulated experience of the advanced enterprises of the industry are considered; the main objectives which can be solved in technological processes of freights handling and forwarding on terminal technology with application of logistic and economic mathematical methods are formulated; specific features of optimization of the operating plan of forwarding activity of the terminal are considered; statement and creation of the terminal operation planning logistic economic-mathematical model is executed, the choice of model optimization criterion in the form of freight handling and long-distance forwarding costs taking into account indicators of the terminal operation planning quality is reasonable
\end{abstract}

\section{Problem statement}

The main objectives of operational planning include ensuring coordinated operation of all links of production, identification of additional reserves of the overworking, throughput and carrying opportunities of motor transport and technical means of the terminal, their correct use for successful performance of plan targets on freight handling and long-distance forwarding.

\section{Analysis of the main achievements and publications}

Solving problems of transport service of the branches of the national economy demands the analysis of domestic and foreign experience [1,2].

In the system of the long-distance transportation of goods (LDTG), the value of

\footnotetext{
* Corresponding author: kafedraturizma02@gmail.com
} 
terminals is defined by their role in implementation of technological process of transportations [3-6]. However, researchers note that process of cargo delivery is often accompanied by losses: deterioration and full or partial loss of goods; delayed transportation and warehousing, poorly organized loading and unloading; and excessive unproductive expenses [7-9].

The quality of transport logistics service which domestic carriers and terminal complexes can provide fail to meet the requirements of the European and international standards. In this regard, $70-75 \%$ of transit freight traffics are taken by foreign companies $[10,11]$. Meanwhile foreign experience shows that warehouse business is being integrated into the large logistic companies and terminals. It allows rationalizing the process of the cargo movement, provides economy on systemic expenses and obtaining the maximum economic effect in the sphere of production, distribution and consumption of goods and services [12-13].

In transport literature issues of general performance of the enterprises are rather well studied $[14,15]$. Optimization of traffic flows and stocks of freights generally is the result of logistic operations [16]. Development optimization of transport and logistics system development is necessary for the purpose of complete solution of problems of the concept transport problems [17]. Currently, a number of federal, regional and municipal programs and projects are being developed and implemented, the elements of which are macroscopic systems $[18,19]$.

\section{Allocation of unresolved parts of common problem}

The most characteristic reasons of deviations arising at implementation of the daily plan of transportation of goods are lack of vehicles for transportation, the insufficient number of the cargo handling gears (CHG) and personnel. Noted defects can be basically eliminated due to improvement of quality of operational planning of operation of the terminal.

The feature of the operating plan optimization of the terminal forwarding activity consists in choosing the best option of freight handling and forwarding organization which takes into account the technical condition of the terminal facilities, parameters of technological processes, freight traffics and volumes of forwarding, temporary characteristics of the carried out operations is considered.

The purpose of article is theoretical justification and development of effective methods of operation of terminals due to improvement of operational planning system.

\section{Statement of the main material of probem}

The formulated problem covers the entire process of transportations from arrival of freights on the terminal up to sending to consignees, unloadings and receipts of new consignments. The system of operational planning of operation of the terminal constructed on the basis of logistic approach is directed to the choice of the most effective forms of the organization of transportation process and performance of the complex of the transport-forwarding services (TFS) accompanying it, ensuring further drop of transport expenses of the national economy.

Cutting freight handling and long-distance forwarding costs is important reserve of increase in overall performance of the cargo terminal and therefore the minimum of costs of implementation of loading and unloading, warehouse works and performance of forwarding operations is accepted as optimality criterion of logistic model of the terminal operation planning problem. Besides, the criterion considers quality indicators of functioning of the terminal to which idle time of the rolling stock, PRM and personnel belong. The optimality 
of criterion function is reached on condition of full use of limited material and human resources $[19,20]$.

Thus, the purpose of problem of operational planning is the optimization of activity of the cargo terminal for rational use of the rolling stock, technological base and human resources to ensure the planned volume of freights handling and forwarding at minimum cost [21].

The general statement and creation of the terminal operation planning economicmathematical model is as follows.

Terminals send shipment from the consignor's warehouses to warehouses of the consignee (direct option) and also from own warehouses. Look $k$ freights $(k=1 \ldots K)$ are transported by the small, average and large-capacity $j$-go cars of type $(j=1 \ldots J) q_{j}$ loading capacity on $m$ route of transportations $(m=1 \ldots M)$. Efficiency of run on route $-\beta_{m}$. The transported freight provides use of loading capacity of the rolling stock according to $j_{k}$ coefficient. The operating plan of operation of the terminal represents the daily plan, namely $N$ - the mass of freight which can be accepted from suppliers, is sent to consignees or left on temporary storage.

For cargo handling the terminal is equipped with type PRM s-go in number of $B_{s}(s=$ $1 \ldots S)$, and also warehouses $r(r=1 \ldots R)$. $P_{r}$ - corresponds to extreme lot of storage of freights on $r$-m warehouse. At this $W_{s}$ - productivity of PRM $s$-go at loading unloading per day; $g_{1 . r k}, g_{2 . r k}$ - the mass of $k$-go of freight which is stored on $r$-ohm terminal warehouse for the beginning and the end of day according to $(k=1 \ldots K ; r=1 \ldots R)$.

The cars necessary for implementation of the daily plan of freight forwarding and handling, conditionally are divided into two streams: $A_{j}$ - the type $j$-go cars $(j=1 \ldots J)$ perform work on delivery and export of freight. The entering and leaving car traffics, in turn, are divided as follows:

$x_{1, j k m s}$ - the number of the j-go cars of type which have arrived with $k$-m freight on $m$ to route of transportations and remained not unloaded by the end of day, unit $(j=1 \ldots J ; k=$ $1 \ldots K ; m=1 \ldots M ; s=1 \ldots S$.

$x_{2 . j k m s}$ - the number of the $j$-go cars of type which have arrived with $k$-m freight on $m$ to route of transportations and unloaded by $s$ the PRM type on warehouse of the terminal, unit $(j=1 \ldots J ; k=1 \ldots K ; m=1 \ldots M ; s=1 \ldots S)$;

$y_{1 . j \mathrm{kms}}$ - the number of the $j$-go cars of type intended for work on $m$ to route of the transportations which are standing idle waiting for discharging of PRM $s$-go or receiving $k$ go of type of cargo, unit $(j=1, \ldots J: k=1, \ldots . K: m=1, \ldots M: s=1, \ldots . S)$;

$\mathrm{y}_{2 . \mathrm{jkms}}$ - the number of the $j$-go cars of type loaded by $s$-m the PRM type, in unit $(j=$ $1 \ldots J ; k=1 \ldots K ; m=1 \ldots . . M ; s=1 \ldots S)$;

$y_{3 . j k m s}$ - the number of the $j$-go cars of type which are taking out $k$-y freight on $m$ to route of transportations by direct option, unit $(j=1 \ldots J ; k=1 \ldots K ; m=1 \ldots M)$.

In time in dress of $T_{n}$ the $j$-go car of type stands idle waiting for loading unloading of $s$-m the PRM $t_{p r j}$ type and transports on $m$ route with $V_{t j}$ speed, at the same time it carries out $a_{j m}$ the goer.

For determination of total size of expenses the following designations are entered.

Expenses on:

$C_{s}$ - loading unloading of $1 \mathrm{t}$ of freight of $s$-m the PRM type, rub $(s=1 \ldots S)$;

$S_{s k l}$-warehouse processing of $1 \mathrm{t}$ of freight in terminal warehouses within a day, rub;

$S_{\text {eksp }}$ - performance of forwarding operations, rub;

$S_{p r j}-1 \mathrm{~h}$ idle time of the $j$-go car of type, $\operatorname{rub}(j=1 \ldots J)$;

$S_{p r s}-1 \mathrm{~h}$ idle time of PRM $s$-go of type, $\operatorname{rub}(s=1 \ldots S)$.

Terminal costs of freight handling and forwarding consists of the following elements:

1. The sum of expenses on the terminal per day: 


$$
\begin{aligned}
& \sum_{j=1}^{J} \sum_{k=1}^{K} \sum_{n=1}^{N} \sum_{s=1}^{S} C_{s} q_{j} j_{k} a_{j m} x_{1 . j k m s}+\sum_{j=1}^{J} \sum_{k=1}^{K} \sum_{n=1}^{N} \sum_{s=1}^{S} C_{s} q_{j} j_{k} a_{j m} x_{2 . j k m s}+ \\
& \sum_{j=1}^{J} \sum_{k=1}^{K} \sum_{n=1}^{N} \sum_{s=1}^{S} C_{s} q_{j} j_{k} a_{j m} y_{1 . j k m s}+\sum_{j=1}^{J} \sum_{k=1}^{K} \sum_{n=1}^{N} \sum_{s=1}^{S} C_{s} q_{j} j_{k} a_{j m} y_{2 . j k m s} .
\end{aligned}
$$

2. Sum of costs of warehouse transactions of the terminal per day

$$
\left(\sum_{r=1}^{R} \sum_{k=1}^{K} g_{1 . r k}+\sum_{j=1}^{J} \sum_{k=1}^{K} \sum_{n=1}^{N} \sum_{s=1}^{S} q_{j} j_{k} a_{j m} x_{2 . j k m s}-\sum_{j=1}^{J} \sum_{k=1}^{K} \sum_{n=1}^{N} \sum_{s=1}^{S} q_{j} j_{k} a_{j m} y_{2 . j k m s}\right) \cdot C_{s k l} \cdot
$$

3. Cost of performance of forwarding operations.

$\left\{\sum_{j=1}^{J} \sum_{k=1}^{K} \sum_{n=1}^{N} \sum_{s=1}^{S}\left[q_{j} j_{k} a_{j m}\left(x_{1 . j k m s}+x_{2 . j k m s} y_{1 . j k m s}+y_{2 . j k m s}\right)\right]+\sum_{j=1}^{J} \sum_{k=1}^{K} \sum_{n=1}^{N} \sum_{s=1}^{S}\left[q_{j} j_{k} a_{j m} y_{3 . j k m s}\right\} C_{e k s p}\right.$.

4. The cost of losses from idle time of cars on the terminal per day

$$
\sum_{j=1}^{J} \sum_{k=1}^{K} \sum_{n=1}^{N} \sum_{s=1}^{S}\left(x_{1 . j k m s}+y_{1 . j k m s}\right) \cdot C_{p r j} t_{p r j} \cdot
$$

5. The size of losses from idle time of PRM

$$
\sum_{s=1}^{S} Z_{s} \cdot t_{p r_{s}} \cdot C_{p r_{S}}
$$

where $Z_{s}$ - quantity of idle PRM

The problem is solved at the following restrictions:

1 . The number of the $j$-go cars of type with $k$-m freight which need to be unloaded on the terminal and the cars which have remained not unloaded from last day does not exceed total number of the $j$-go cars of type to which TEU on import have to be rendered per day:

$$
\sum_{k=1}^{K} \sum_{n=1}^{N} \sum_{s=1}^{S}\left(x_{1 . j k m s}+x_{2 . j k m s}\right) \leq A_{j}
$$

for $j=1 \ldots J ; k=1 \ldots K ; m=1 \ldots M ; s=1 \ldots S$.

2. The number of the $j$-go cars of type which are taking out $k$-y freight on $m$ to route from warehouses of consignors; cars which have to be loaded the $s-\mathrm{m}$ the PRM type in terminal warehouses according to the plan of the forthcoming day and cars which are standing idle waiting for discharging of PRM or receiving freight from last day does not exceed total number of cars which need to be loaded according to the plan.

$$
\sum_{k=1}^{K} \sum_{m=1}^{M}\left(y_{3, j k m s}+\sum_{s=1}^{S}\left(y_{1, j k m s}+y_{2, j k m s}\right) \leq H j,\right.
$$

для $j=1 \ldots J ; k=1, \ldots K ; m=1, \ldots M ; s=1 \ldots . S$.

3. The quantity of PRM s-go of type used for loading unloading does not exceed their total on the terminal

$$
\frac{1}{W_{s}} \cdot \sum_{j=1}^{J} \sum_{m=1}^{M} q_{j} j_{k} a_{j m}\left(x_{1 . j k m s}+x_{2 . j k m s}+y_{1 . j k m s}+y_{2 . j k m s}\right)+Z_{s}=B_{s},
$$

where $j=1 \ldots J ; m=1 \ldots M$.

4. The rest of freights in terminal warehouses by the end of the planned day is equal to the sum of the passing rest of freights from last day and the arrived shipment minus the mass of the freights sent from terminal warehouses 


$$
\sum_{k=1}^{K} q_{2 r k}=\sum_{k=1}^{K} q_{1 r k}+\sum_{k=1}^{K} j_{k} \sum_{j=1}^{J} q_{j} \sum_{m=1}^{M} a_{j m} \sum_{s=1}^{J}\left(x_{1 . j k m s}+x_{2 . j k m s}-y_{2 . j k m s}\right),
$$

for each $r=1 \ldots R$.

$$
\sum_{k=1}^{K} q_{2 r k}=\sum_{k=1}^{K} q_{1 r k}+\sum_{k=1}^{K} j_{k} \sum_{j=1}^{J} q_{j} \sum_{m=1}^{M} a_{j m} \sum_{s=r+1}^{J}\left(x_{1 . j k m s}+x_{2 . j k m s}-y_{2 . j k m s}\right),
$$

for each $r=1 \ldots R ; j=1 \ldots J ; k=1 \ldots K ; m=1 \ldots M ; s=1 \ldots S$.

The rest of freights in warehouses of the terminal is not negative and does not exceed the capacity of warehouses.

$$
0 \leq \sum_{k=1}^{K} g_{2 . r k} \leq \mathrm{P}_{r}
$$

for each $r=1 \ldots R ; k=1 \ldots K$.

5. The volume of the freights (import plus export) handled by the terminal and warehousing do not exceed the planned building of the terminal for day

$$
\sum_{j=1}^{j} q_{j} a_{j m} \sum_{k=1}^{K} j_{k}\left[y_{3 . j k m s}+\sum_{s=1}^{S}\left(x_{1 . j k m s}+x_{2 . j k m s}+y_{2 . j k m s}\right)\right]=N,
$$

for each $j=1 \ldots J ; k=1 \ldots K ; m=1 \ldots M ; s=1 \ldots . S$.

6. At the same time the requirement of nonnegativity of variables has to be fulfilled

$$
x_{1 . j k m s} \geq 0 ; \quad x_{2 . j k m s} \geq 0 ; y_{1 . j k m s} \geq 0 ; y_{2 . j k m s} \geq 0 ; y_{3 . j k m s} \geq 0 \text {. }
$$

Vector argument in the formulated problem of $x_{j}$ - the number of cars necessary for implementation of the program of transportations of $N$.

$$
X_{j}=\sum_{j=1}^{J} \sum_{k=1}^{K} \sum_{m=1}^{M}\left[\sum_{s=1}^{S}\left(x_{1 . j k m s}+x_{2 . j k m s}+y_{1 . j k m s}+y_{2 . j k m s}\right)+y_{3 . j k m s}\right]+\sum_{s=1}^{S} Z_{s},
$$

for each $j=1 \ldots J$.

Criterion function of model has appearance:

$$
\begin{gathered}
F=\sum_{s=1}^{S}\left\{\sum _ { j = 1 } ^ { J } \sum _ { k = 1 } ^ { K } \sum _ { m = 1 } ^ { M } \left\{q _ { j } j _ { k } a _ { j m } \left[\left(C_{p r s}+C_{e k s p}\right) x_{1 . j k m s}+\left(C_{p r s}+C_{s k l}+C_{e k s p}\right) x_{2 . j k m s}+\right.\right.\right. \\
\left.\left.+\left(C_{p r s}+C_{e k s p}\right) y_{1 . j k m s}+\left(C p r_{s}-C_{s k l}+C_{e k s p}\right) y_{2 . j k m s}\right]+C_{p r j}\left(x_{2 . j k m s}+y_{1 . j k m s}\right)\right\}+C_{p r s} Z_{s} \cdot t_{p r s}+ \\
+\sum_{j=1}^{J} \sum_{k=1}^{K} \sum_{m=1}^{M}\left(q_{j} j_{k} a_{j m} y_{3 . j k m s}\right) C_{e k s p}+\sum_{k=1}^{K} \sum_{r=1}^{R} C_{s k l} \cdot g_{1 . r k} \rightarrow \mathrm{min}
\end{gathered}
$$

Calculation of the task mathematical model is carried out on stages.

First of all, the car traffic which is subject to loading in the passing direction is allocated. Thus, drawing up the operating plan of operation of the terminal consists in determination of necessary quantity of PRM and cars for long-distance forwarding by direct option; in optimization of operation of the terminal on handling small batch and the container freights followed by the transfer through warehouse.

\section{Conclusions}

As a result of solving the problem of operational planning of operation of the terminal, the necessary number of cars for routes of transportations is determined, including the optimum number of cars which have to be sent on the corresponding loading and unloading points and are sent by the terminal by direct option, cargo balances in terminal warehouses are 
passed.

To optimal variant of functioning of the terminal there corresponds the minimum sum of freight handling and forwarding costs, including costs for forwarding cars in the direction of travel and also losses from different idle times of vehicles and PRM. The developed economic-mathematical model of process of operational management is applicable for any terminal systems. Results of calculation can be used for analysis and identification of reserves for cost saving for the purpose of increase in efficiency and quality of transportforwarding services. The mathematical model of the task is carried out in stages.

\section{References}

1 L.B. Mirotin. Integrated logistics of accumulative and distributive complexes (warehouses, transport hubs, terminals). M.: Examination, 448 (2003)

2 N.P.Zhuravlev, O.B. Malikov. Transport and cargo systems. M - the Route, (2006).

3 O.B. Malikov. Warehouses and cargo terminals. M.: - Business-Pressa publishing house. (2005).

4 A.M. Gadzhinsky. Modern warehouse. Organization, technology, steering and logistics. M.: - Shopping Mall Velbi, Publishing house the Avenue, - 2005.

5 I.M. Trunina, V.G. Zagoryansky, E.L. Zaroryanskaya, D.V. Maloshtan: International Journal of Engineering \& Technology, 7., 4.3, 537-540 (2018)

6 N.V. Napkhonenko. Scientific thought of the Caucasus, 1, 82-94 (2004).

7 T.A.Prokofieva, O.M. Lopatkin. Logistics of transport and distributive systems: Regional aspect, M.: RKonsult, 400 (2003)

8 V.V. Dybskaya [etc.]. Logistics: integration and optimization of logistic business processes for deliveries. M.: Eksmo, 939 (2014)

9 A.V. Velmozhin, V.A.Beeps, L.B. Mirotin. Theory of the organization and steering of automobile transportations: logistic aspect of formation of transportation processes. Volgograd: RPK «Politekhnik», 179 (2001)

10 D. Shekhter. Logistics. Management skill supply chains. M.: Alpina, 452 (2013)

11 Yu. M. Nerush. Supply and transport: effective interaction. M.: Economy, (1999)

12 J.Evers, L.Loeve, D.Lindeijer. New Logistic Control: Concepts, Architecture and Logistics Programming. 3-th Intermational Meeting for Researth in Logistics. TroisRivieres, Canada, 15 (2000)

13 D. Bauersosk, D. Klos. Logistics: the integrated chain of the deliveries. M.: CJSC Olympe-business, 640 (2001)

14 E.A.Kravchenko, A.V.Woman's, E.N. Ushmayev. Basic researches, 12, 61-65 (2007)

15 Element R. Basic, D.Cox, R. Brown. Information and risk in the marketing. M.: Finstatinform, 374 (1993)

16 A.A. Bakayev. Mathematical methods in planning and economic calculations. M.: Science. 223 (1987)

17 N.V. Napkhonenko, D.M. Zagirnyak. International Journal of Engineering \& Technology. 7, 4.3, 185-190 (2018)

18 I.Kabashkin. Logistics. 3 (2001)

19 N.V. Napkhonenko. Izv. higher education institutions. Sowing. - Kavk. region. Tekhn. Sciences, Special issue, 141-146 (2003)

20 H.Yu. Eldarkhanov. Transport and logistics: monograph. Tambov: Diploma, 214 (2008)

21 N.V. Napkhonenko. Scientific thought of the Caucasus, 1, 82-94 (2004) 